\title{
RENEGOTIATION AND SPECIFIC PERFORMANCE
}

\author{
Tracy R. Lewis, * Martin K. Perry, $†$ and David E.M. Sappington**
}

\section{INTRODUCTION}

This article will examine the implications of enforcing specific performance for attempted breach of contract in a model of renegotiation. It will be shown that after the supplier receives relevant private information, renegotiation does not always occur even though gains from trade exist. Further, this article will argue that enforcement of specific performance can result in a higher level of expected social welfare, appropriately defined, relative to the case where monetary damages for breach of contract are permitted.

Specific performance, as the name implies, is the requirement that the exact terms of a contract be fulfilled. Specific performance is not the common remedy for breach of contract. It is generally enforced only when money damages provide inadequate relief for breach of contract. However, as this article will attempt to show, the threat of specific performance can provide desirable incentive features. Thus, specific performance might deserve more careful attention than it has heretofore been afforded.

As noted, courts generally grant specific performance only when money damages are inadequate. This situation typically occurs when the buyer has no substitute for the contracted performance. For example, when the performance in question involves such commodities as land, heirlooms, antiques, patents, copyrights, or businesses, the uniqueness of these items makes it difficult to assess adequate monetary compensation for the buyer when the supplier refuses to perform. The Uniform Commercial Code § 2716(1) (1987) expands upon the uniqueness standard by stating that "[s]pecific performance may be decreed where the goods are unique or in other proper circumstances." The "other proper circumstances" are not defined fully in the official comments; but the comments suggest that the "inability to cover" by purchasing substitute goods would be strong evidence in favor of granting specific performance.

\footnotetext{
Copyright $\odot 1989$ by Law and Contemporary Problems

- Professor of Economics, University of California, Davis.

$\dagger$ Technical Staff, Bellcore. Visiting Professor of Economics, Rutgers University.

* Technical Staff, Bellcore. Professor of Economics, University of Florida.
}

The views expressed in this paper are not necessarily those of Bellcore. We are grateful to the participants in this symposium for their helpful comments, particularly Jerome Culp, Daniel Graham, Jerry Green, and Dale Stahl. 
Provisions of this sort have not traditionally been applied in commercial settings. Since substitute goods or alternative suppliers are usually available, commercial goods rarely satisfy the "uniqueness" test or the "inability to cover" test. Thus, specific performance has seldom been granted for breach of short-term commercial contracts. ${ }^{1}$ Since breach of long-term commercial contracts raises further difficult issues in assessing money damages, courts have occasionally granted specific performance in these cases. ${ }^{2}$

The argument against the expanded use of specific performance is that its use might increase undesirable rent-seeking, and also increase negotiation costs. To illustrate, suppose a new buyer turns out to value the supplier's goods more highly than the original contracting buyer. The ability to renegotiate the original contract allows the supplier to avoid specific performance. This prevents an inefficient use of the goods by the original buyer, or a costly additional transfer of the goods from the original buyer to the new buyer. However, the threat of enforcing specific performance could enable the contracting buyer to extract some of the gain in efficiency that arises from selling the goods to the new buyer. To avoid such rent-seeking, the courts should only employ specific performance when it is impossible to

1. Recent decisions have indicated an expansion of the use of specific performance for onetime commercial contracts. Perhaps the most notable cases involved cotton futures contracts during the mid-1970's. See Linzer, On the Amorality of Contract Remedies-Efficiency, Equity, and the Second Restatement, 81 Colum. L. Rev. 111,129 (1981). Many farmers defaulted on their agreement to deliver cotton at 30 cents per pound when the market price approached one dollar per pound. Despite the relatively homogeneous nature of cotton and the existence of well-organized markets for cotton, most courts required the farmers to deliver the cotton as promised (that is, specific performance was ordered). Some courts referred to the prevailing scarcity of cotton; others noted that buyers were committed to resale contracts.

Obligations of the buyer on related contracts were also cited as a reason for granting specific performance in Ace Equip. Co. v. Aqua Chem., Inc., $73 \mathrm{~Pa}$. D. \& C.2d 300 (1975). In this case, the buyer had agreed to resell a used electrical transformer that had been promised to him by a supplier. The supplier initially failed to deliver the transformer, but the court ordered specific performance. The court pointed out that the buyer could be liable for speculative and extensive consequential damages for failure to perform on the resale contract.

2. The official comments to U.C.C. $\$ 2-716(1)$ (1987) do suggest that specific performance is suitable for requirements contracts. There are a number of instances where specific performance has been granted in the case of long-term contracts. Some cases involve raw materials whose uniqueness is derived from their scarcity and important specialized uses. But other cases involve raw materials that are readily available on spot markets. The most notable case is Laclede Gas Co. v. Amoco Oil Co., 522 F.2d 33 (8th Cir. 1975). Amoco agreed to supply propane to Laclede, but in the winter of 1972-73 Amoco was unable to fulfill all of its contracts for propane. It announced that previous requirements would be reduced by $80 \%$. Id. at 36 . Laclede sued for breach of contract and asked for specific performance. The Eighth Circuit granted the request even though propane was readily available on the spot market, although at higher prices. The court reasoned that it would be difficult and costly for Laclede to enter into alternative long-term contracts for propane. Indeed, the court stated that expert testimony indicated Laclede most likely could not find a replacement long-term contract. It also concluded that money damages would be difficult to calculate for a long-term contract in light of the uncertainty in the world energy markets. Id. at 40.

Similarly, in Eastern Air Lines, Inc. v. Gulf Oil Corp., 415 F. Supp. 429, 442 (S.D. Fla. 1975), the court granted specific performance of a long-term contract in which Gulf agreed to supply aviation fuel to Eastern. See Axelrod, Specific Performance of Contracts for Sales of Goods: Expansion or Retrenchment in the 1980's, 7 VT. L. REv. 249, 262-63 (1982); Greenberg, Specific Performance under U.C.C. $\$ 2-716$ : "A More Liberal Attitude" in the "Grand Style," 87 Cом. L.J. 583, 597 (1982). 
calculate the monetary damages incurred by the contracting buyer from breach of contract. $^{3}$

The theory often advanced in the legal community for expanded use of specific performance is that specific performance can fully protect the subjective value of the contract to the non-breaching party. Schwartz has argued that money damages typically undercompensate the non-breaching party. ${ }^{4}$ Buyers often find it difficult to recover damages for the incidental costs incurred in obtaining substitute goods, employing less suitable goods, and delaying production, for example. Schwartz also disputes the contention that use of specific performance will lead to excessive rent-seeking. Therefore, he recommends expanded use of specific performance by the courts. He also suggests that parties be allowed to contract for specific performance in the same fashion that they now contract for liquidated damages. ${ }^{5}$

This article will examine renegotiation of an initial contract where specific performance can be enforced in the event of attempted breach. One purpose in doing so is to demonstrate the gains that arise when specific performance can be threatened in the event of attempted breach. A second purpose is to characterize the nature of the renegotiation that ensues when specific performance can be enforced.

The contract setting we consider is a one-time transaction involving commercial goods. The goods need not be "unique" in the legal sense of not being able to fashion an adequate money damage award. Thus, the initial contract is not one that would normally meet the requirements for specific performance in the event of attempted breach. However, there are no legal or economic reasons for ruling out specific performance in this setting. In particular, there is little difficulty in specifying and monitoring performance in the environment we consider. ${ }^{6}$ Thus, one could envision more liberal legal

3. Several authors have argued that this is the practical intent of imposing the "uniqueness" test in the common law and the "inability to cover" test of the U.C.C. They argue further that the goal of contract law should be to specify the remedy that the parties would have optimally chosen ex ante. See R. Posner, Economic Analysis of Law 105-14, 117-19 (1986); Muris, The Costs of Freely Granting Specific Performance, 1982 DuKE L.J. 1059, 1064-68.

4. Schwartz, The Case for Specific Performance, 89 Yal.e L.J. 271, 291-96 (1979). See also Linzer, supra note 1 , at 111, 131-34 (courts should base their choice between money damages and specific performance remedies on the basis of which best protects the subjective value of the non-breaching party); Kronman, Specific Performance, 45 U. CHI. L. Rev. 351, 362-63 (1978) (courts are more likely to undercompensate the non-breaching party when damages are difficult to assess. Therefore, these are the instances where the court should select specific perfornnance.); Ulen, The Efficiency of Specific Performance: Toward a Unified Theory of Contract Remedies, 83 Mich. L. REv. 341, 364-66 (1984).

5. Schwartz, supra note 4, at 291-96. Of course, some limitations on the remedies would remain. For example, explicit penalties would not be permitted in a liquidated damage remedy. In addition, impossibility would be a defense to the specific performance remedy.

6. For simplicity, it is assumed that the goods are homogeneous and not identified to this particular contract. In cases where the goods are identified, specific performance might be enforceable under the provisions of U.C.C. $\$ 2-716(e)(3)$.

It should also be noted that damages might be difficult to calculate in this setting because the buyer must investigate the cost of covering with substitute goods. In general, the minimal costs of cover will not be publicly known. Similarly, the buyer's efforts in searching for substitute goods may be difficule to verify. 
criteria for the grant of specific performance by the courts. Alternatively, one might envision the courts routinely enforcing a contract drawn up by two parties in which specific performance is specified as the only adequate remedy.

In our model, after a simple initial contract is agreed to by a buyer and supplier, only the supplier, and not the buyer, learns the price that other firms are willing to pay for goods in his inventory. This price is also the unit cost at which the supplier can secure additional supply of the good if needed for delivery. This price information that the supplier learns could lead to incentives for renegotiation of the original contract. We examine the nature of a particular form of negotiation in which the buyer is endowed with all of the bargaining power. ${ }^{7}$

Formally, the model begins at time $T_{0}$ when a buyer and supplier meet. At this time, the supplier's resources are limited. In particular, he cannot post any monetary bond with the buyer that would ensure future performance. Nor can he purchase any inventory of the good in question for future delivery to the buyer unless the buyer finances the purchase. ${ }^{8}$ At this initial time, $T_{0}$, the two parties share the same imperfect knowledge about the price the good in question will command at the critical future date, $T_{1}$, when the buyer is to consume the good. ${ }^{9}$ (See Figure 1.) They also share the same perfect knowledge of the unit price, $c^{e}$, at which the good can be purchased immediately. $c^{e}$ is also the expected value of the corresponding price for the good at time $T_{1}$.

When the buyer and supplier meet at time $T_{0}$, the buyer finances a purchase of $Q_{1}$ units of the good (or product) at $\operatorname{cost} c^{e} Q_{1}$ with the stipulation that they be delivered to her by the supplier at time $T_{1}$ in return for a payment of $P_{1}$ dollars. This is the initial agreement between buyer and supplier. In essence, the buyer endows the supplier with an inventory of the critical product, with the stipulation that the entire inventory be delivered to the buyer at date $T_{1}$ in return for a payment of $P_{1}$, unless a different mutually advantageous arrangement is agreed to during renegotiation at time $T_{1} \cdot{ }^{10}$

The supplier plays a non-trivial role in this model because he acquires perfect knowledge of the selling price of the product at time $T_{1}$. Because she is removed from the process, the buyer never acquires this information. She

7. We endow the buyer with the ability to propose a "take it or leave it" renegotiation schedule to the supplier; but under the specific performance remedy we consider, the supplier can always insist on the terms of the original contract, which he initially found to be in his own interest to sign.

8. This is obviously an extreme assumption. These qualitative conclusions are largely unaltered if the supplier's resources are limited, but greater than zero. The key requirement is that the supplier's wealth be less than the maximum potential total net surplus from the contracting relationship.

9. One might think of the buyer as a producer and the good in question as a critical input in her production process. $T_{1}$, then, would represent the date at which the buyer must undertake her production.

10. For simplicity, we abstract from both a formal production process and any third party who might lend resources to the supplier in order to finance production. Both possibilities could readily be included in our model. 
can only rely on the supplier to convey information about the opportunity value of the inventory with which he has been endowed.

During the renegotiation that occurs at time $T_{1}$, the buyer can propose alternative delivery-payment $\{Q, P\}$ combinations from which the supplier can select; or the supplier can abide by the terms of the initial contract $\left(Q_{1}\right.$, $\left.P_{1}\right)$.

The following conclusions arise from this simple model:

(1) For a range of intermediate realizations of opportunity cost, $c$, no renegotiation of the initial contract will occur. The supplier will deliver $Q_{1}$ units of output in return for the compensation, $P_{1}$, that was originally agreed upon.

(2) For the smaller realizations of $c$, more of the product $\left(Q>Q_{1}\right)$ will be delivered. However, the quantity delivered will be less than the efficient quantity, $Q^{*}(c)$, which maximizes the combined welfare of the buyer and supplier.

(3) For the higher realizations of $c$, renegotiation will result in less output $\left(Q<Q_{1}\right)$ being delivered; but the quantity delivered will exceed the efficient amount $Q^{*}(c)$.

The model also demonstrates that social welfare can be increased when specific performance is enforced, rather than allowing the supplier to compensate the buyer for any damages incurred due to breach of the initial contract.

The analysis proceeds as follows. In Part II, the model is described in detail, and the problem under consideration is stated formally. Our main conclusions are stated and explained in Part III. Alternative remedies for breach of contract are considered in Part IV. Summary comments are offered in Part V.11

\section{II}

\section{Description of the Model}

The model includes two parties: a buyer and a supplier. The supplier purchases and delivers a product that the buyer values. The benefit that the buyer derives from the purchase of $Q$ units of the product is $B(Q) .^{12}$

The supplier can sell his product to either the buyer or other customers at date $T_{1}$. The unit price that these other customers are willing to pay at date $T_{1}$ is unknown when the buyer and supplier sign a contract at date $T_{0}$ for delivery of the product. At time $T_{0}$, this future price or opportunity cost, $c$, is a random variable. ${ }^{13}$ Thus, the buyer and supplier share the same imperfect knowledge of the ultimate value of the opportunity cost when they sign the initial contract.

11. Formal proofs of our findings are omitted, but are analogous to those presented in Lewis \& Sappington, Inflexible Rules in Incentive Problems, 79 AM. Econ. REv. 69, 82 (1989).

12. To capture the phenomenon of diminishing returns, we assume $B^{\prime}(Q)>0$ and $B^{\prime \prime}(Q)<0 \forall$ $Q>0$, where prime functions denote derivatives.

13. We assume $f(c)>0 \forall \in[\underline{c}, \bar{c}]$. 
FIGURE 1

Timing in THE Model

\begin{tabular}{cc} 
Initial & \\
contract & Supplier \\
$\left(Q_{1}, P_{1}\right)$ & learns \\
signed & $c$ \\
\hline
\end{tabular}

\begin{tabular}{cc}
$\begin{array}{c}\text { Buyer } \\
\text { proposes } \\
\text { renegotiation } \\
\text { options }\end{array}$ & $\begin{array}{c}\text { Supplier } \\
\text { chooses } \\
\text { preferred } \\
(Q, P) \text { option }\end{array}$ \\
\hline
\end{tabular}

$T_{0}$

$T_{1}$

The initial contract between buyer and supplier specifies the quantity of the product, $Q_{1}$, that is to be delivered at date $T_{1}$, and the corresponding compensation, $P_{1}$. As noted above, it is the buyer who finances the purchase of the $Q_{1}$ units of the product at total cost $c^{e} Q_{1}{ }^{14}$ Such financing is required because the supplier has no wealth initially. Once the parties sign the contract for delivery at date $T_{0}$, we assume that either party can enforce specific performance without cost. Thus, unless the initial contract $\left(Q_{1}, P_{1}\right)$ is renegotiated, the supplier must deliver $Q_{1}$ units of output to the buyer, and the buyer must pay the supplier $P_{1}$ dollars.

The initial contract between buyer and supplier is exogenous. It might arise, for example, as the outcome of a bargaining process. Some further thoughts on the likely origins and characteristics of $\left(Q_{1}, P_{1}\right)$ are offered in Part $V .{ }^{15}$ At this juncture, two comments about the initial contract are warranted. First, the initial contract is a simple one in that a single delivered quantity and a single payment are specified. Second, the delivery level, $Q_{1}$, is assumed to be bounded in that it is less than the quantity that is efficient for the lowest cost realization, but greater than the quantity that is efficient for the highest cost realization. ${ }^{16}$

When the parties sign the initial contract, they realize that renegotiation might occur at the delivery time, $T_{1}$, when the supplier resolves his initial uncertainty about his opportunity cost of delivery. At time $T_{1}$, the supplier observes the realization of $c$ and thereby learns the unit price at which he can either sell the $Q_{1}$ units he has acquired to other customers or purchase additional supplies for his inventory. The buyer never observes the realization of $c$. When the value of $c$ is high, the supplier can earn relatively large profits if he is allowed to sell his inventory to outside buyers, rather than delivering the $Q_{1}$ units he promised to the buyer in the initial contract. When the value of $c$ is small, however, the supplier cannot secure large profits from

14. Recall that $c^{e}$ is the expected value of the random variable $c$ :

$$
c^{e}=\int_{c}^{\bar{c}} f(c) d c
$$

15. See infra p. 48.

16. $Q_{1} \in\left(Q^{*}(\bar{c}), Q^{*}(c)\right)$. The reason for this restriction will be made clear in Part III, infra. In Part V infra, we argue that the buyer will optimally choose $Q_{1} \in\left(Q^{*}(\bar{c}), Q^{*}(c)\right)^{\prime \prime}$ when she is free to structure the initial contract as well as subsequent renegotiation. Throughout, we assume that $Q^{*}(\bar{c})$ $>0$ and $Q^{*}(\underline{c})<\infty$. 
selling his inventory, and may prefer to purchase additional units of the product and sell them to the buyer.

The model simulates the possibility of renegotiation at time $T_{1}$ as follows: the buyer proposes alternative delivery payment pairs $(Q P)$; the supplier can either choose one of these pairs, or insist on the original contract $\left(Q_{1}, P_{1}\right)$. In effect, then, the buyer has all of the bargaining power at the renegotiation stage, since she is the one permitted to make the "take it or leave it" offer to the supplier.

Despite the asymmetry in the parties' bargaining power at the renegotiation stage, the buyer's powers are not unlimited in this model. The initial contract must provide the supplier with an expected profit of at least $\bar{\pi}$, even as the parties consider the possibility of renegotiation. For example, $\bar{\pi}$ might represent some expected profit level that the supplier could secure if he chose not to contract with the buyer at all. Given the initial contract $\left(Q_{1}, P_{1}\right)$, the concern is with Pareto-efficient ${ }^{17}$ renegotiation: That is, the buyer chooses the terms of renegotiation to maximize her expected net benefits ${ }^{18}$ while ensuring that the supplier receives the required expected profit level, $\bar{\pi}$. Roughly speaking, as the value of $\bar{\pi}$ increases, the greater is the presumed bargaining power of the supplier. ${ }^{19}$

The supplier's profit is derived from two sources: compensation from the buyer and compensation through sales to other customers. Thus, with inventory $Q_{1}$, if $Q$ units are ultimately delivered to the buyer in return for total payment $P$, the supplier's profit will be $P+c\left[Q_{1}-Q\right]$. As noted above, in this calculation $c$ represents the unit price other customers will pay for the product; it also represents the unit price at which the supplier can acquire additional units of inventory at date $T_{1}$ to sell to the buyer. The supplier will either buy or sell inventory at time $T_{1}$ to maximize his profits; his decision will depend upon the realization of $c$ and the terms of the renegotiation offered by the buyer. ${ }^{20}$

The contracting problem can be described in the following manner. The buyer designs the contract to maximize the expected difference between her direct benefits $B(\cdot)$ and her payments to the supplier $P(\cdot) .^{21}$ The supplier's goal is to maximize his expected profit. The solution requires that several

17. Defined in H. Varian, Microeconomic Analysis 57-58 (1978).

18. $(B(\cdot)-P)$.

19. $\bar{\pi}$ is assumed to be strictly less than the expected surplus from efficient production,

$$
\text { i.e., } \bar{\pi}<\int_{\underline{c}}^{\bar{c}}\left[B\left(Q^{*}(c)\right)-c Q^{*}(c)\right] f(c) d c \text {, where } Q^{*}(c)=\underset{Q}{\operatorname{argmax}} B(Q)-c \cdot \mathrm{Q} \text {. }
$$

This assumption simply allows for the possibility that gains from contracting are anticipated by the buyer.

20. Recall that the supplier is assumed to have no resources of his own. Thus, if he ends up purchasing additional inventory at time $T_{1}$, he does so (as at time $T_{0}$ ) with funds provided directly from the buyer in the payment $P(\cdot)$. Implicit in this formulation is the assumption that outright theft (or misappropriation) of the buyer's funds by the supplier never occurs.

21.

$$
\underset{Q_{1} Q(\cdot), P(\cdot)}{\text { Maximize }} \stackrel{\tilde{c}}{\int}[B(Q(c))-P(c)] \cdot f(c) d c .
$$


conditions be met in order to guarantee that $(Q(c), P(c))$ is the outcome of the renegotiation process when $c$ is realized. First, the supplier must prefer this outcome to the terms of the original contract. ${ }^{22}$ Second, the buyer must share the same preference. ${ }^{23}$ Third, when $c$ is the supplier's realized opportunity cost, the terms of renegotiation $(Q(c), P(c))$ must provide him with greater profit than any other outcome $(Q(\hat{c}), P(\hat{c}))$ proposed by the buyer. ${ }^{24}$ Finally, when entering into the contract with the buyer, the supplier expects to realize at minimum his reservation profit level, $\bar{\pi} .{ }^{25}$

\section{III}

\section{Solution to the Problem}

Because the initial contract instructs the supplier to acquire some inventory at time $T_{0},{ }^{26}$ the supplier's cost of performing under the contract varies with his private information about the opportunity cost. In particular, when the value of $c$ is small, the supplier's opportunity cost of delivering the $Q_{1}$ is relatively low. In other words, the supplier realizes greater profit if he fulfills the terms of the original contract than if he sells the $Q_{1}$ units from his inventory to outside buyers. Since renegotiation must leave the supplier with higher profit than he would obtain by fulfilling the initial contract, in an important sense the supplier is better off when the realization of $c$ is small, since he can always enforce specific performance if he so chooses. Consequently, the supplier might prefer that the buyer believe $c$ to be even smaller than it actually is. This preference will be more pronounced as $Q_{1}$ increases.

This effect is in direct contrast to the usual incentive of the supplier: to have the buyer believe the value of $c$ is greater than it actually is. As $c$ increases, it is more costly for the supplier to deliver output to the buyer. Therefore, the buyer must pay more for any delivery quantity greater than the contract quantity, $Q_{1}$. The qualitative properties of the solution to $[C P]$ are a direct consequence of these two countervailing effects. ${ }^{27}$

Figure 2 illustrates the solution to $[C P] .{ }^{28}$ For a range of intermediate realizations of the supplier's opportunity cost, no renegotiation occurs; thus,

\footnotetext{
22. $P(c)+c\left[Q_{1}-Q(c)\right] \geqq P_{1} \quad \forall c \in[c, \bar{c}]$.

23. $\quad B(Q(c))-P(c) \geqq B\left(Q_{1}\right)-P \quad \forall c \in[c, \bar{c}]$.

24. $P(c)+c\left[Q_{1}-Q(c)\right] \geqq P(\hat{c})+c\left[Q_{1}-Q(\hat{c})\right] \forall c, \hat{c} \in[\epsilon, \bar{c}]$.

25. $\bar{c}$

$\int_{c}^{c}\left[P(c)+c\left[Q_{1}-Q(c)\right]\right] \cdot f(c) d c \geqq \bar{\pi}$.

26. This is so because $Q_{1}>0$.

27. We assume that $Q_{1} \in\left[Q^{*}(\bar{c}), Q^{*}(c)\right]$ to ensure that both of these effects are reflected in the solution to $[C P]$.

28. (1) $Q(c)=Q_{1} \forall c \in\left[c_{1}, c_{2}\right]$, where $\underline{c}<c_{1}<c_{2}<\vec{c}$;

(2) $Q_{1}<Q(c)<Q^{*}(c) \forall c \in\left(\underline{c}, c_{1}\right)$, where $Q^{*}(c)=\operatorname{argmax} B(Q)-c \cdot Q$;

(3) $Q^{*}(c)<Q(c)<Q_{1} \forall c \in\left(c_{2}, \bar{c}\right)$;

$Q$

(4) $Q(c)=Q^{*}(c)$ for $c=\underline{c}, \bar{c}$;

(5) $P(c)+c\left[Q_{1}-Q(c)\right]=P_{1}$ for $c \in\left[c_{1}, c_{2}\right]$, and $P(c)+c\left[Q_{1}-Q(c)\right]>P_{I}$ for $c \in\left[c_{1}, c_{2}\right]$.
} 
the supplier delivers the output specified in the original contract, and receives the payment to which the parties originally agreed. Renegotiation does occur for the smaller and larger cost realizations. For low values of $c$, more output is delivered to the buyer in return for greater compensation than the parties agreed to in the original contract. When the supplier can command higher prices elsewhere for the units in his inventory, he delivers less to the buyer than he originally agreed to, and his compensation is reduced accordingly. ${ }^{29}$

Generally, renegotiation to the efficient delivery level, $Q^{*}(c)$, does not occur because the actual realization of $c$ is not observed publicly, and deviations in the delivered quantity help to reduce the rents ${ }^{30}$ the supplier can command from his private information. ${ }^{31}$ To see these effects, one can think of the renegotiation process in the following manner: The buyer commits herself to a delivery and payment schedule, $\{Q(\cdot), P(\cdot)\}$. Delivery and payment are indexed by the supplier's report to the buyer of the value of his opportunity cost. Thus, if the supplier reports that $c$ is his realized unit opportunity cost, the buyer will pay $P(c)$ dollars for the delivery of exactly $Q(c)$ units of the product. ${ }^{32}$

Recall the two countervailing incentives that limit the set of renegotiation options available to the supplier during the renegotiation stage. He might want to exaggerate the reported value of his cost of serving the buyer in hope of securing more generous compensation for his product. To mitigate this incentive, the requested delivery quantity falls below the efficient level. The smaller output reduces the potential gains from exaggerating the true marginal cost of supply.

29. Technically, the solution to $[C P]$ has:

$$
B^{\prime}(Q(c))=c+\frac{F(c)}{f(c)} \forall c \in\left[c, c_{1}\right],
$$

and

$$
B^{\prime}(Q(c))=c-\frac{1-F(c)}{f(c)} \forall c \in\left[c_{2}, \bar{c}\right],
$$

where it assumed

$$
\frac{d}{d c}\left\{\frac{F(c)}{f(c)}\right\} \geqq 0
$$

and

$$
\frac{d}{d c}\left\{\frac{1-F(c)}{f(c)}\right\} \leq 0 \quad \forall c \in(\underline{c}, \bar{c}) .
$$

These regularity conditions are common in the literature, see, e.g., Boron \& Besanko, Regulation, Assymetric Information, and Auditing, 15 Rand J. ECON. 447 (1984), and are imposed to ensure that in equilibrium, the output delivered to the buyer is a strictly decreasing function of $c, \forall c \in\left[c, c_{1}\right]$ and $\forall c \in\left[c_{2}, \bar{c}\right]$.

30. Rents refer to profits that accrue to the supplier in excess of his reservation profit level, $\bar{\pi}$.

31. The revelation principle, see Meyerson, Incentive Compatibility and the Bargaining Problem, 46 ECONOMETRICA 61 (1979), ensures there is no loss of generality in representing our problem in this manner.

32. $c \in\left(c, c_{1}\right)$. 
FIGURE 2

The Optimal Contract

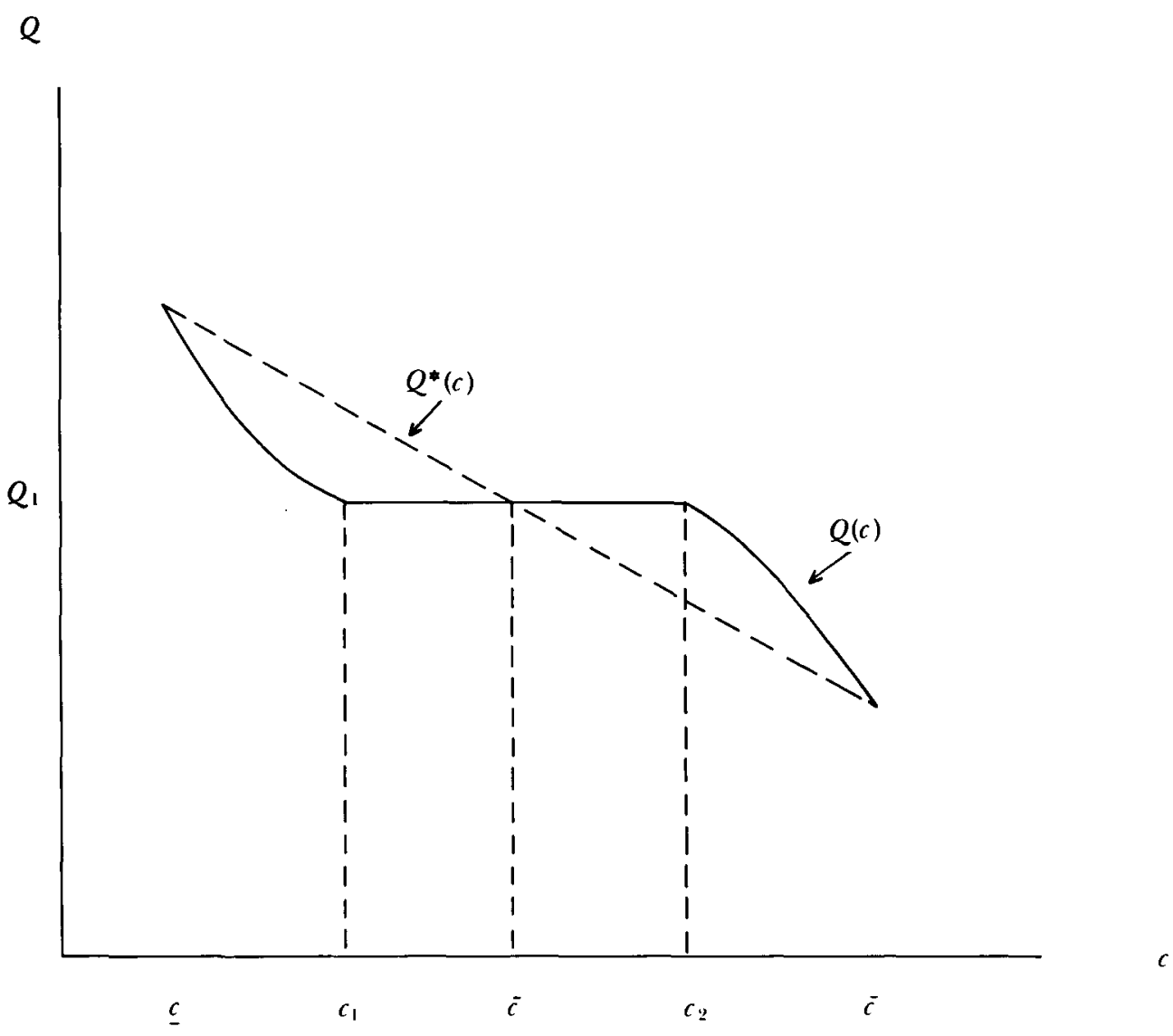

The other incentive that may exist for the supplier is to understate $c$ in order to exaggerate the total profit he would realize if the original contract were not renegotiated. To mitigate this incentive, output in excess of the efficient level is induced. The supplier finds it less attractive to understate $c$ if he must deliver large quantities of output to the buyer while still receiving compensation consistent with his understatement of supply costs.

The solution to $[C P]$ indicates that the supplier's dominant incentive is to exaggerate low realizations of $c,{ }^{33}$ and understate high realizations of $c .{ }^{34}$ To mitigate these incentives, induced delivery levels fall short of the efficient levels for low realizations of $c$ and exceed efficient levels for high realizations of $c .^{35}$ Although these deviations help to limit the gains that the supplier accrues as a result of renegotiation, the gains are not entirely eliminated. ${ }^{36}$

33. $\left.c \in\left(c, c_{\mathrm{t}}\right)\right)$.

34. $c \in\left(\bar{c}_{2}, c\right)$.

35. See supra note 28 , at properties (2) and (3).

36. Id. at property (5). 
The supplier's profit increases through renegotiation when the value of $c$ is low since costs of supply are unexpectedly small. The supplier also realizes increased profit from renegotiation if the value of $c$ is high because the inventory on hand is particularly valuable.

As mentioned, renegotiation does not occur for intermediate cost realizations. ${ }^{37}$ The absence of renegotiation results from the incentive effects just described and the fact that, in any feasible solution to $[C P]$, the quantity delivered to the buyer cannot increase with the supplier's realized opportunity cost. The supplier will deliver a larger quantity only if he is compensated for delivery at a rate that is at least commensurate with his costs. Consequently, if the buyer pays an amount sufficient to induce greater output when costs are high, the supplier will strictly prefer to deliver the larger quantity when costs are low.

Because induced deliveries cannot rise with the value of $c$, the buyer cannot both: (1) induce a delivery quantity below the efficient level for all smaller cost realizations, as would best mitigate the supplier's incentives to exaggerate low realizations; and (2) induce a delivery quantity in excess of the efficient level for all the larger cost realizations, as would best mitigate the supplier's incentives to understate high realizations. The best she can do instead is to induce an intermediate region where deliveries do not vary with costs. Thus, the parties will renegotiate the terms of the original contract for large and small cost realizations, but not for realizations in the intermediate range. ${ }^{38}$

37. Id. at property (1).

38. A simple numerical example helps to illustrate the magnitude of the qualitative effects described above. Suppose the supplier's reservation profit level $\bar{\pi}$ is zero, and the random variable has a uniform distribution over the unit interval (that is, $f(c)=1 \quad \forall c \in[0,1])$. Further suppose the benefits the buyer derives at time $T_{1}$ from $Q$ units of the product is $B(Q)=a Q-b Q^{2}$, where $a \geq 1$ and $b>0$ are constants.

In this setting, if the buyer could directly observe the unit cost $c$ of the product at $T_{1}$ and make purchases herself, she would purchase $Q^{*}(c)$ units when $c$ is realized, where

$$
Q^{*}(c) \equiv \underset{Q}{\operatorname{argmax}} a \cdot Q-b \cdot Q^{2}-c \cdot Q=\frac{a-c}{2 b} .
$$

Figure A illustrates this efficient delivery schedule. Also depicted in Figure A is the optimal delivery schedule, $Q(c)$, that would operate when only the supplier can observe the realization of $c$. This solution to the contracting problem $[C P]$ for the present example is given by:

$$
Q(c)=\left\{\begin{array}{l}
Q^{*}(c)-\frac{c}{2 b} \text { for } c \in\left[0, \frac{1}{4}\right] ; \\
Q_{1}=\frac{2 a-1}{4 b} \text { for } c \in\left[\frac{1}{4}, \frac{3}{4}\right] \\
Q^{*}(c)+\frac{1-c}{2 b} \text { for } c \in\left[\frac{3}{4}, 1\right] .
\end{array}\right.
$$


IV

Monetary Damages

An alternative remedy to specific performance is the payment of monetary damages. Monetary damages can alter the opportunity set for the supplier, ${ }^{39}$ and thereby alter both the gains from renegotiation and the expected

\section{FIGURE A}

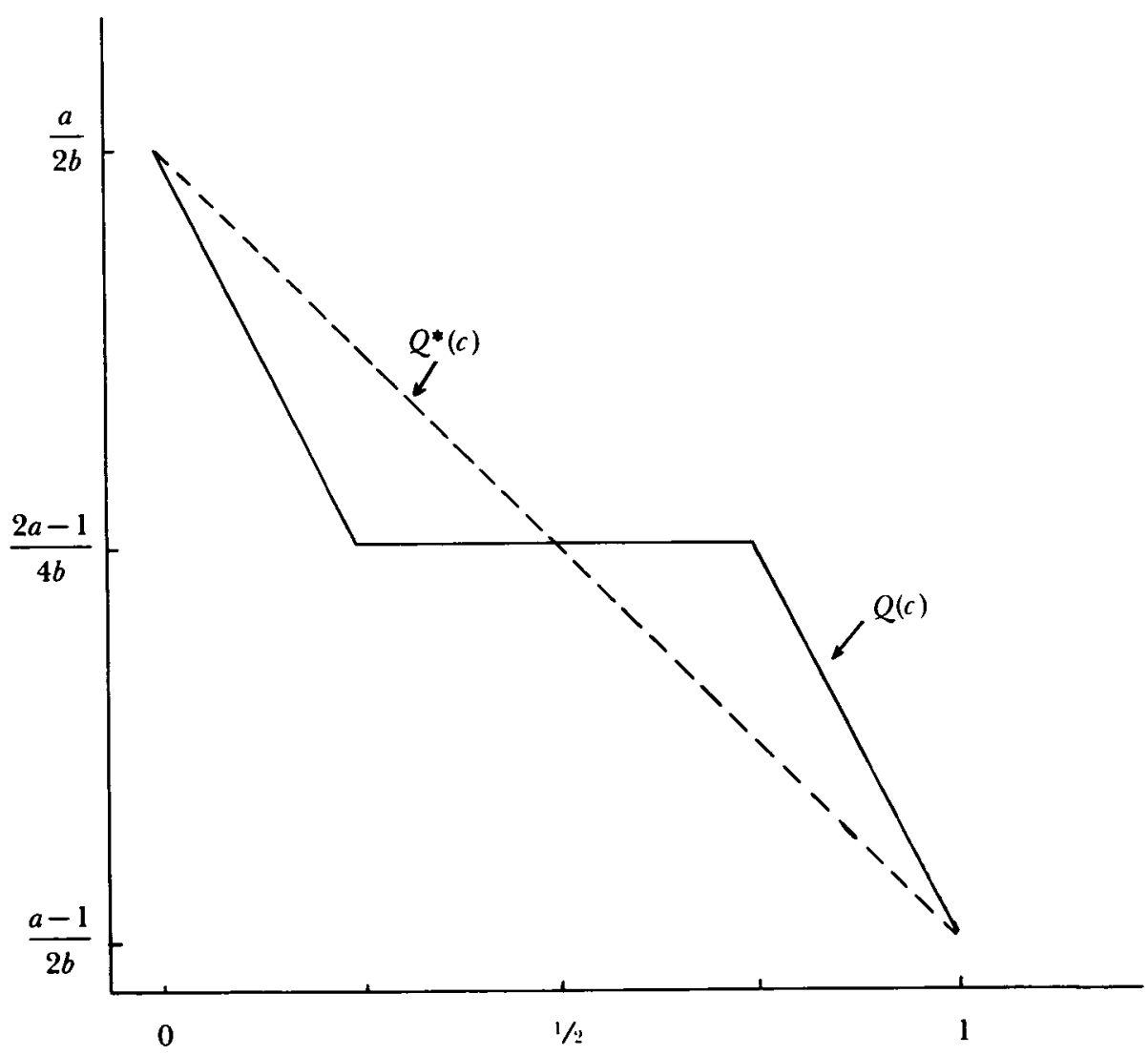

It is also straightforward to verify that in this situation, the expected profit of the supplier is $\frac{1}{192 b}$. The expected gain in net benefits for the buyer compared to what she could secure simply by purchasing $\bar{Q}$ units of the product at time $T_{0}$, where

$$
\bar{Q}=\underset{Q}{\operatorname{argmax}} a \cdot Q-b \cdot Q^{2}-\frac{1}{2} \cdot Q,
$$

is readily shown to be $\frac{2}{192 b}$. Thus, two-thirds of the increment in total expected surplus that arises from the presence of an informed (although self-interested) supplier in this example is captured by the buyer, and the remaining one-third accrues to the supplier.

39. The opportunity set is the set of options available to the supplier. 
aggregate welfare that arises under any initial contract. There are two methods for calculating the monetary damages a supplier must pay if he fails to deliver the promised output at time $T_{1}$. First, if there were other goods available that the buyer could readily substitute for the contracted goods, she could cover by purchasing these substitutes, and subsequently sue the supplier for the difference between the cover price and the contracted price. ${ }^{40}$ If $r$ were the unit cover price, then damages would be equal to $r Q_{1}-P_{1}$. One could model the cover price as arising in much the same random fashion in which the supplier realizes his opportunity cost. In particular, at time $T_{1}$ the buyer might obtain a verifiable observation on the price of alternative goods. If the total cover price exceeds the buyer's required payment, ${ }^{41}$ the buyer's realized cost of covering exceeds the payments she originally agreed to make.

Second, if cover is not possible, damages could be calculated as the net benefit the buyer foregoes under the initial contract. ${ }^{42}$ These lost benefits are the consequential losses that the buyer would incur either from discontinuing production or from producing without the supplier's goods.43 For example, these losses could simply be the profits the buyer would have received under a prior contract with a third party-a contract she can only fulfill if the supplier does not breach. ${ }^{44}$

The effect of introducing either damage measure will generally be to increase the ex post profit the supplier can guarantee himself under the original contract $\left(Q_{1}, P_{1}\right)$ when compared to the profit he could ensure if specific performance were the only remedy for breach of contract. If cover were possible, but the cover price exceeds the highest possible opportunity cost, breach would never occur. The supplier's ex post profit would match that realized under specific performance for all cost realizations. However, if cover were possible and the cover price exceeds the highest possible opportunity cost, the supplier would breach and pay damages for cost realizations higher than the cover price. Thus, in this region, the profits the supplier can guarantee himself if the buyer covers are higher than if specific performance of the initial contract were the remedy for attempted breach.

The second "lost benefits" measure of damages will alter the supplier's opportunity set in a similar fashion. If the buyer's benefits from the promised output exceed the maximum possible cost of producing this output, damages will be so large that the supplier will never breach. However, if the buyer's benefits are not that large, then for the high cost realizations ${ }^{45}$ the supplier

40. See U.C.C. $\$ 2-712$ (1962).

41. $r \cdot Q_{1}>P_{1}$.

42. $B\left(Q_{1}\right)-P_{1}$.

43. See U.C.C. \& 2-717 (1962).

44. Note that the benefits and losses we speak of here must be verifiable by a court; but we have assumed throughout that the function $B\left(Q_{1}\right)$ is common knowledge.

45.

$$
\forall c \geq c^{D} \equiv \frac{B\left(Q_{1}\right)}{Q_{1}} .
$$


will prefer to breach, to compensate the buyer for her losses, and to sell his inventory to other customers at the realized price.

Figure 3 illustrates this point. Line segment $S S^{\prime}$ traces the minimal profit the supplier is guaranteed by the original contract under specific performance. The slope of line segment $S S^{\prime}$ is zero because under specific performance, the supplier simply turns over to the buyer the units that she has already purchased. Thus, realized profits are independent of the realization of $c$. $S S D^{\prime}$ indicates the corresponding minimal profit locus when damages are a remedy option available to the supplier. The kink occurs when the cover price equals the supplier's opportunity cost, in the case of cover, and at $c=c^{D}$ in the case of lost benefits. Minimal profits increase with opportunity cost at a rate equal to the level of the supplier's inventory along line segment $D D^{\prime}$. In this region, all inventory sold is at price $c$ and, absent renegotiation, none is delivered to the buyer.

These observations are important because the introduction of monetary damages for breach of contract in lieu of specific performance grants the supplier additional freedoms, and thereby restricts the possibilities available to the buyer. Consequently, the introduction of this option (weakly) reduces the buyer's expected net benefits. Since the analysis can be interpreted as a problem of social welfare maximization, ${ }^{46}$ social losses result when the contract includes the possibility of monetary damages for breach. Hence, when renegotiation is possible, (weak) Pareto gains are feasible when the parties exclude damage measures and enforce specific performance in the event of attempted breach.

This result implies that a routine grant of specific performance would increase aggregate expected welfare, but reduce the surplus of the supplier. Of course, suppliers might share in the social gains from specific performance if specific performance is a contract term over which the parties can negotiate before signing a contract.

\section{V}

\section{ConcLusion}

This article demonstrates that, in the presence of asymmetric information between the buyer and supplier, enforcement of specific performance may increase social welfare. As a result of countervailing incentives for the supplier introduced in the renegotiation process, the supplier's profit gain is limited to less than that realized when monetary damages are available.

This article also discusses the nature of the renegotiation process. In particular, for intermediate realizations of the unit value of the good, no renegotiation occurs. For high values of the good, the supplier delivers fewer units than the number initially agreed to, but this amount exceeds the efficient amount that would maximize the combined welfare of the buyer and supplier. Conversely, for low values of the good, the supplier delivers a higher quantity

46. Where weights $a>\frac{1}{2}$ and $1-a$ are placed on the welfare of the buyer and seller, respectively. 
Figure 3

\section{Minimal Profit Loci}

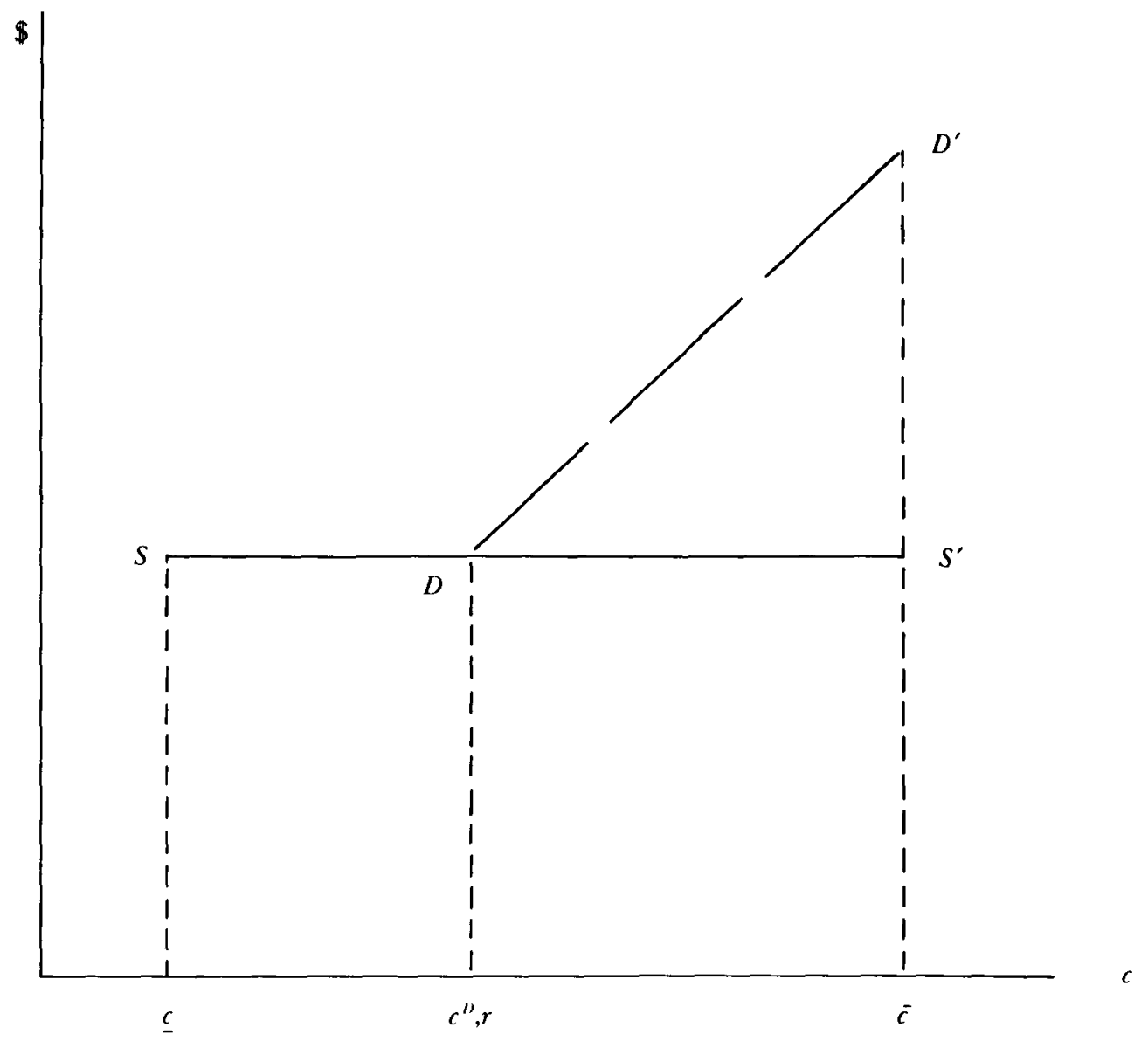

than agreed to, but this quantity is less than the efficient amount. When the simple initial contract is chosen optimally by the buyer, the intermediate range of value realization in which the parties choose not to renegotiate the contract can be quite sizable (recall that in note 38 this range constituted 50 percent of the entire range of possible cost realization). Hence, the model may provide some insight into why contracts are not renegotiated in practice, even when strict Pareto gains could be achieved if the supplier's private information were observed publicly.

The analysis to this point has taken the initial contract as given. In fact, it is possible to show that when the buyer can choose $\left(Q_{1}, P_{1}\right)$ as well as the renegotiation schedule, she will chose a delivery quantity somewhere between the efficient level of output at the highest and lowest realization of $c .{ }^{47}$ Thus, the assumption maintained throughout the discussion will be satisfied. Therefore, the only real restriction of the analysis is the convention that a

47. $Q_{1} \in\left(Q^{*}(\bar{c}), Q^{*}(\underline{c})\right)$. See Lewis \& Sappington, supra note 11 
single delivery-payment pair $\left(Q_{1}, P_{1}\right)$ constitutes the entire initial contract between buyer and supplier. ${ }^{48}$ Such a restriction might be justified on grounds of normal practice or because the costs of writing more complicated contracts are excessive. Of course, such restrictions should be modeled formally and analyzed carefully.

48. More generally, the initial contract might consist of an entire menu of $(Q P)$ pairs. If this were possible, and if the risk-neutral supplier had more wealth $(W)$ than the maximum possible expected net benefits to the buyer from operation (that is, if

$$
\left.\left.W>\int_{\underline{c}}^{\bar{c}}\left[B\left(Q^{*}(c)\right)-c Q^{*}(c)\right] f(c) d c-\bar{\pi}\right]\right),
$$

the efficient outcome could always be ensured, and the supplier's expected profits could be held to $\bar{\pi}$. For details, see Harris \& Raviv, Optimal Incentive Contracts with Imperfect Information, $20 \mathrm{~J}$. ECON. THEORY 231 (1979). 